\title{
Functional Analysis of Chalcone Synthase (Chs) Gene in Indian Wheat Cultivars in Response to Peg-Induced Drought Stress
}

\author{
Megha Singh*, Vaishali and Lalit Kumar
}

Sardar Vallabhbhai Patel University of Agriculture and Technology, Meerut: 250010 College Of Applied Education and Health Sciences, Meerut-250001, India

*Corresponding author

\section{Keywords}

Chalcone synthase gene, Drought stress, Functional analysis,

Polyethylene glycol, RNA extraction

\section{Article Info}

Accepted: 07 September 2020 Available Online: 10 October 2020

\section{A B S T R A C T}

PEG- based in-vitro screening for drought tolerance has been proven to be a suitable method to effectively screen large sets of germplasm with good accuracy. In response to stress, plants produce secondary metabolites that stimulate the induction of different biochemical alterations which include synthesis of preventive phenolic compounds. CHS acts as the front-end coordinator of flavonoid biosynthesis and its regulation. The expression of CHS gene is affected by biotic and abiotic factors as well as pathogen attack. The aim of this study was to analyse the expression profile of CHS in wheat genotype under imposed drought stress. For this purpose 20 wheat genotypes were treated with different concentration of PEG to imposed rought condition. The result shows very high expression value of CHS gene for genotype HD2733 and K9107 as compared to genotype DBW71 and PBW553 at every level of polyethylene glycol concentration under imposed drought stress condition.

\section{Introduction}

CHS plays an important role as it is the first committed enzyme in the flavonoid pathway. It is responsible for the biosynthesis of various types of metabolites in different plant parts. CHS becomes activated only under specific environmental factors. Stressed conditions are an important factor for the onset of CHS transcription. Induced activity of CHS was reported under UV-light in parsley cell cultures (Schroder and Schaafer, 1980). Chalcone synthase (CHS) is the mother enzyme which steps in the flavonoid pathway and further produce flavonoids, isoflavanoid-type phytoalexins and other metabolites to prevent plants against stress. CHS gene expression is induced in plants under abiotic and biotic stress conditions. CHS elaborates phenylpropanoid pathway 
which acts as precursors to a wide range of plant metabolites that are important to human health as antioxidants, anti-inflammatory agents, anti-allergens and even anti-oncogenic products. Being aromatic compounds, flavonoids strongly absorb UV light through a photoreceptor-mediated mechanism which effectively protects the plants from DNA damage. Flavonoid gene expression, their accumulation are closely related to drought stress. A chalcone synthase $(\mathrm{CHS}) \mathrm{cDNA}$ clone from parsley was the first flavonoid biosynthetic gene to be isolated (Kreuzaler et al., 1983). As CHS is representative of plant polyketide synthase superfamily, synthesizes flavonoids that provide flower pigments, protection against biotic-stress factors, UV-light (Hahlbrock and Scheel 1989). CHS provides the entry point and catalyses the stepwise condensation of one $p$-coumaryl-CoA and three malonyl-CoA molecules, which is formed via acetyl-CoA metabolism, to yield narengeninchalcone, the precursor for a large number of flavonoids (Weisshaar and Jenkins, 1998; Claudotet al., 1999; Lunkenbein et al., 2006). Chalcones and dihydrochalcones are considered to be the primary precursors and constitute the main intermediates for flavonoid synthesis (Marais et al., 2006).

An increased level of chalcone synthase (CHS), a crucial enzyme in flavonoid/ isoflavonoid biosynthesis pathway, also interacting with methyl jasmonate and salicylic acid (SA) signaling (Dao et al., 2011) was found in a drought-sensitive sunflower genotype under dehydration (Ghaffari et al., 2013). In a study on wheat by Ma et al., 2014 reported higher genes expression levels of TaCHS, TaCHI, TaF3H, TaFLS, TaDFR, and TaANS, flavonoids biosynthesis genes in response to drought stress. Induction of chalcone synthase in plants is drastically affected by environment and different growth stages of plant. The regulation is controlled by both metabolically and transcriptionally via controlling the regulation of CHS gene (Martin 1993). Research works had been conducted that showed inhibition of CHS via flavonoid pathway intermediates like naringenin, chalconenaringenin and other resulting products of Co-A esters (Dao et al., 2011).The control on the regulation of CHS transcription is also done by environmental factors and developmental stages (Dixon et al., 1994; Harrison et al., 1991). Different CHS promoter sequences are involved in tissue specific CHS expression was reported in Petunia (Van der Meer et al., 1990, 1993). The regulatory factors responsible for controlling CHS in plants are managed with help of specific loci. Doonerin 1983 studied four loci, cl, r, vp and clf that participate during the control of CHS expression in maize. The increased activity of CHS and high accumulation of flavonoids restrict the transport of auxin which as a result provides biotic resistance in many cases (Brown et al., 2001; Faulkner and Rubbery 1992; Jacobs and Rubbery 1988). Jasmonic acid produced at wounded or infected sites triggers the activation of CHS which as a result produces different compounds in order to make plant tolerant towards the injury or stressed conditions.

The production of secondary metabolites in plants is in the connection of stress management. Here, we investigated the expression profile of flavonoids biosynthesis gene (CHS) in response to drought stress

\section{Materials and Methods}

\section{Functional analysis of flavonoid biosynthesis gene in response to drought stress}

\section{Chalcone synthase gene primer}

Designed Chalcone synthase gene primer was reported in earlier studies custom synthesized 
from Bangalore Eurofins Genomics Pvt. Ltd., India.

\section{RNA extraction}

To study the effect of drought on plant, the sample was collected on $10^{\text {th }}$ day after germination from control and treatments of 4 wheat varieties which performed well in above experiments. The collected leaves were immediately dipped in liquid nitrogen and stored for RNA isolation.

The total RNA was isolated using RNA isolation kit (BangloreGenei) following the manufacture instructions. As the RNA is very much sensitive to RNAse activity hence the care should be taken and autoclaved DEPCtreated water was used to inactivate RNAse as described. All the glass wares and plastic wares were dipped in autoclaved DEPC treated water for at least $12 \mathrm{~h}$ at $37^{0} \mathrm{C}$. Thereafter, these glass wares were autoclaved, and then glass wares and others were baked at $25^{0} \mathrm{C}$ for $4-12 \mathrm{hrs}$, before use for RNA isolation. Electrophoresis apparatus was also cleaned with $0.5 \%$ SDS solution washed with DEPC treated autoclaved water and finally treated with $3 \% \quad \mathrm{H}_{2} \mathrm{O}_{2}$ for 1 hrs. All the solutions including Tris buffer were made in DEPC treated water then autoclaved and stored. Disposable gloves were changed frequently during the experiment.

For isolation of total RNA, 0.5 gm of leaf was crushed in liquid nitrogen until it becomes a fine powder. $2 \mathrm{ml}$ Eppendorf tube was filled up to one third with frozen powder. $1 \mathrm{ml}$ of RNA extraction solution was added and vortex vigorously, then $200 \mu \mathrm{l}$ of chloroform was added and vortex again. Samples were kept on ice and then incubated on a shaker for 10 minute at room temperature. The eppendorf were centrifuged at 13,500 rpm for 10 minutes at $4^{\circ} \mathrm{C}$. Supernatant was taken in a fresh eppendorf tube and $850 \mu \mathrm{l}$ chloroform was added and vortex for 15 seconds. The tubes were then centrifuged at 13,500 rpm for 15 minutes at $4^{\circ} \mathrm{C}$. Supernatant was transferred in a fresh Eppendorf tube and added $1 \mathrm{ml}$ isopropanol then vortex and incubate for $2 \mathrm{hr}$ at $-20^{\circ} \mathrm{C}$. The tubes were centrifuged at 13,500 for 20 minutes. Supernatant was discarded and pellet was washed with $900 \mu \mathrm{l}$ of $70 \%$ ethanol. Pellets were dried until the white pellets became clear. Then, $53 \mu 1 \mathrm{H}_{2} \mathrm{O}$ was added and pellet was dissolved by vigorous vortexing several times. Centrifugation was done at $13,500 \mathrm{rpm}$ for $10 \mathrm{~min}$. $50 \mu \mathrm{l}$ of the RNA solution was transferred to a new reaction tube (leaving behind polysaccharide slime) and subjected for purification.

\section{Purification of RNA}

Before using the RNA as template for RTPCR, a DNAse treatment was performed in order to eliminate the presence of eventual DNA contamination in the samples. For this purpose take $15 \mu \mathrm{l}$ of extracted RNA sample and added $2 \mu \mathrm{l}$ of DNAse $(1 \mathrm{U} / \mu \mathrm{l})$ and $3 \mu \mathrm{l}$ of DEPC water in a total of $20 \mu 1$ of reaction mixture. The reaction was incubated at $37^{\circ} \mathrm{C}$ for 1 hour and Inactivation of enzyme was done at $95^{\circ} \mathrm{C}$ for 10 minutes.

\section{Quantification of total RNA and electrophoresis}

The spectrophotometric determination of quantity of total RNA was done by using Nanodrop Nd-1000 UV/Vis spectrophotometer. The quantity of total RNA was determined from the absorbance at 260 $\mathrm{nm}$ and its quality was assessed by A260/A280 ratio. Further, total RNA quality and quantity was assessed by fractionation on $1 \%$ formaldehyde agarose gel that was prepared by boiling agarose in $82 \mathrm{ml}$ running buffer and adding $18 \mathrm{ml}$ formaldehyde after cooling it at $65^{\circ} \mathrm{C}$ temperature. 


\section{cDNA preparation}

cDNA was synthesized, using total RNA as template, with Oligo dT (18 mer) primers. Reaction was performed in $20 \mu 1$ of volume with high fidelity MMLV reverse transcriptase enzyme. For this $5 \mu \mathrm{l}$ of total RNA (1 $1 \mu \mathrm{g})$ was taken and added $1 \mu \mathrm{l}$ of oligo dT (18mer, $10 \mu \mathrm{m})$ with $5 \mu$ l of DEPC water. The reaction was incubated for $5 \mathrm{~min}$. at $70^{\circ} \mathrm{C}$ to disrupt the secondary structure of RNA molecule and then added $4 \mathrm{ml}$ of enzyme buffer [5x], $2 \mu 1$ of dNTPs (2.5 mM each) and $2 \mu l$ of DEPC water. The reaction mixture was incubated at $37^{\circ} \mathrm{c}$ for 5 minute and added $1 \mu \mathrm{l}$ of MMulLv $(5 \mathrm{U} / \mu \mathrm{l})$. The samples were incubated at $42^{\circ} \mathrm{C}$ for 1 hour. Synthesized cDNA were stored at $-20^{\circ} \mathrm{C}$ for the regular use. Thermal profile reaction for cDNA preparation is given in table 1 .

\section{Quantitative expression profile of Chalcone Synthase gene through Real Time PCR}

To study the expression profile of $\mathrm{CHS}$ in wheat genotype the quantitative PCR amplification was done using gene specific primer synthesized from Bangalore Eurofins Genomics Pvt. Ltd., India. qCHS: FATGGCGGCTACAATGACG, RTGTGCTCGCTCTTGGTGA. The primers were diluted in TE buffer solution for making primer stocks and later further diluted to $300 \mathrm{nM}$ final working concentrations using ion free double distilled water.

The reaction was performed in a real time PCR detection system using Bio Rad RT-PCR kit with SYBR Green. $10 \mu \mathrm{L}$ of the reaction mix containing $5 \mu \mathrm{L}$ qPCR SYBR GREEN PCR Master Mix, $0.5 \mu \mathrm{L}$ diluted cDNA template and $0.5 \mu \mathrm{L}$ both forward and reverse primer were added into each well. The thermal cycling profile was recommended by the manufacture: $95^{\circ} \mathrm{C}$ for $10 \mathrm{~min}, 40$ cycles of $95^{\circ} \mathrm{C}$ for $15 \mathrm{~s}, 60^{\circ} \mathrm{C}$ for $30 \mathrm{~s}$. To confirm the specificity of the primers, melting curves were included after amplification. All the samples for qRT-PCR analysis were conducted with three biological replicates each comprising three technical replicates. The relative $\Delta \mathrm{Cq}$ value was calculated by formula $(\mathrm{Ct}$ control- $\mathrm{Ct}$ treatment), where $(\mathrm{Ct}$ control $=\mathrm{ct}$ value of housekeeping gene and $\mathrm{Ct}$ treatment $=\mathrm{Ct}$ value of target gene) and the expression fold was calculated by $\Delta \Delta \mathrm{Cq}=2-\Delta \mathrm{Cq}$.

\section{Results and Discussion}

The expression of flavonoid biosynthesis gene and their accumulation are closely related to drought stress. The activity of flavonoid structural genes is mainly regulated at transcriptional level. The Chalcone synthases (CHS) provides the entry point and catalyze the production of chalcone which is the primary precursor for flavonoid biosynthesis. The expression of wheat Chalcone Synthase gene was studied in the diverse wheat genotype to understand the role of TaCHS gene under drought condition.

To study the expression pattern and the role of CHS gene under drought stress, the 4 wheat genotypes viz. HD2733, PBW533, DBW71 and K9107 were taken on the basis diversity and their response under drought stress for various characters. The green leaves samples for these four varieties were collected after the treatment of different concentration of polyethylene glycol for RNA isolation. The total RNA was isolated and cDNA was prepared for all four genotypes and used to amplify with gene specific primers qCHS for CHS gene. 
Table.1 Thermocycler Program for the PCR-based marker amplification

\begin{tabular}{|lcll|}
\hline Steps & Temperature & Time & Number of cycles \\
\hline Initial denaturation & $94^{\circ} \mathrm{C}$ & $3 \mathrm{~min}$ & 1 (first) \\
Denaturation & $94{ }^{\circ} \mathrm{C}$ & $1 \mathrm{~min}$ & \\
Annealing* & 50,55 or $60{ }^{\circ} \mathrm{C}$ & $1 \mathrm{~min}$ & \\
Elongation & $72^{\circ} \mathrm{C} \quad 2 \mathrm{~min}$ & $35 \mathrm{Cycles}$ \\
Final elongation & $72^{\circ} \mathrm{C}$ & $5 \mathrm{~min}$ & 1 Cycle \\
& $12^{\circ} \mathrm{C}$ & forever & until turn off \\
*depending on individual microsatellite & & \\
\hline
\end{tabular}

Figure.1 Expression profile shown by HD 2733 and K 9107 in control and all three treatment of polyethylene glycol using CHS primer

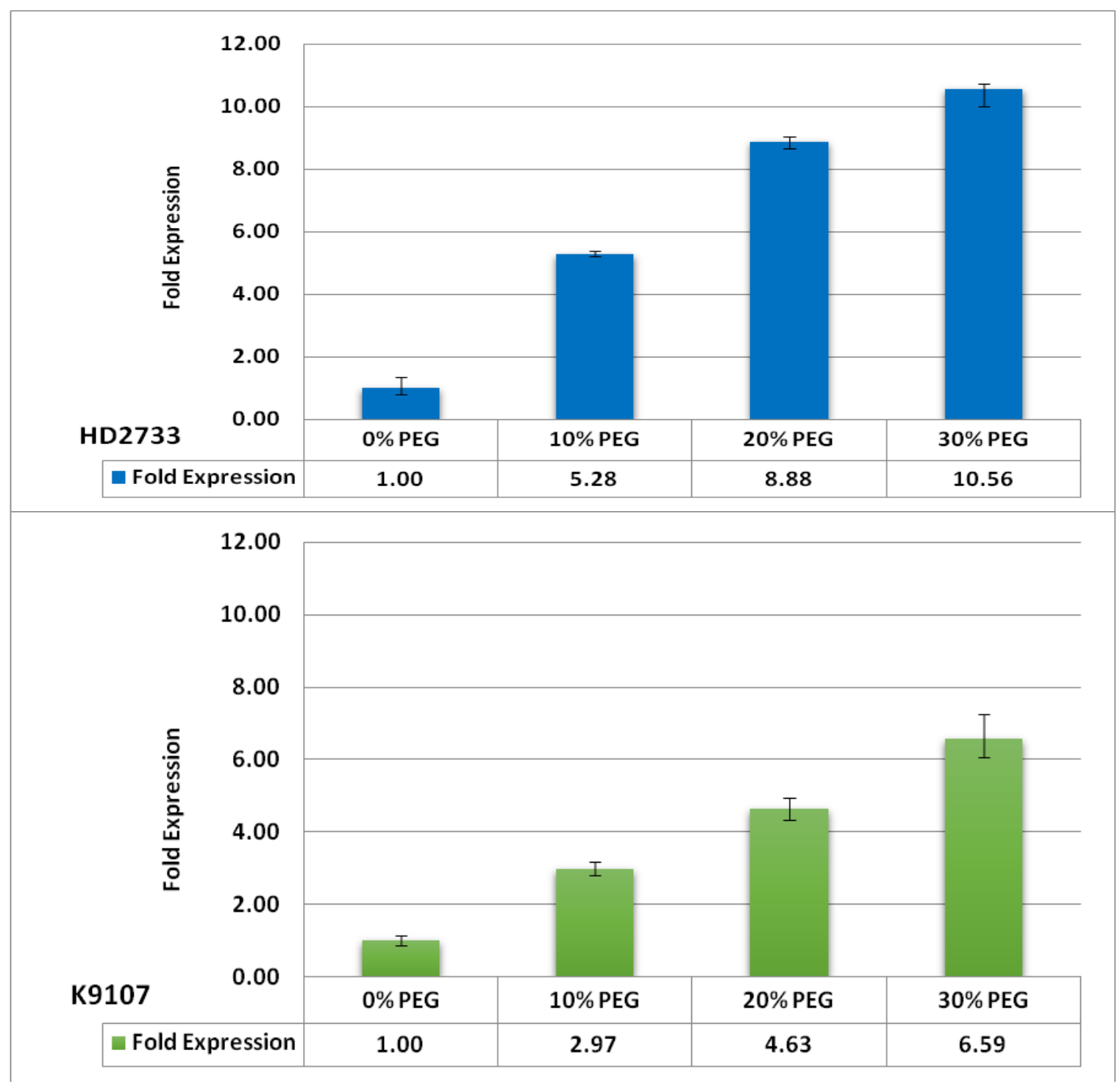


Figure.2 Expression profile shown by DBW 71 and PBW 533 in control and all three treatment of polyethylene glycol using CHS prime
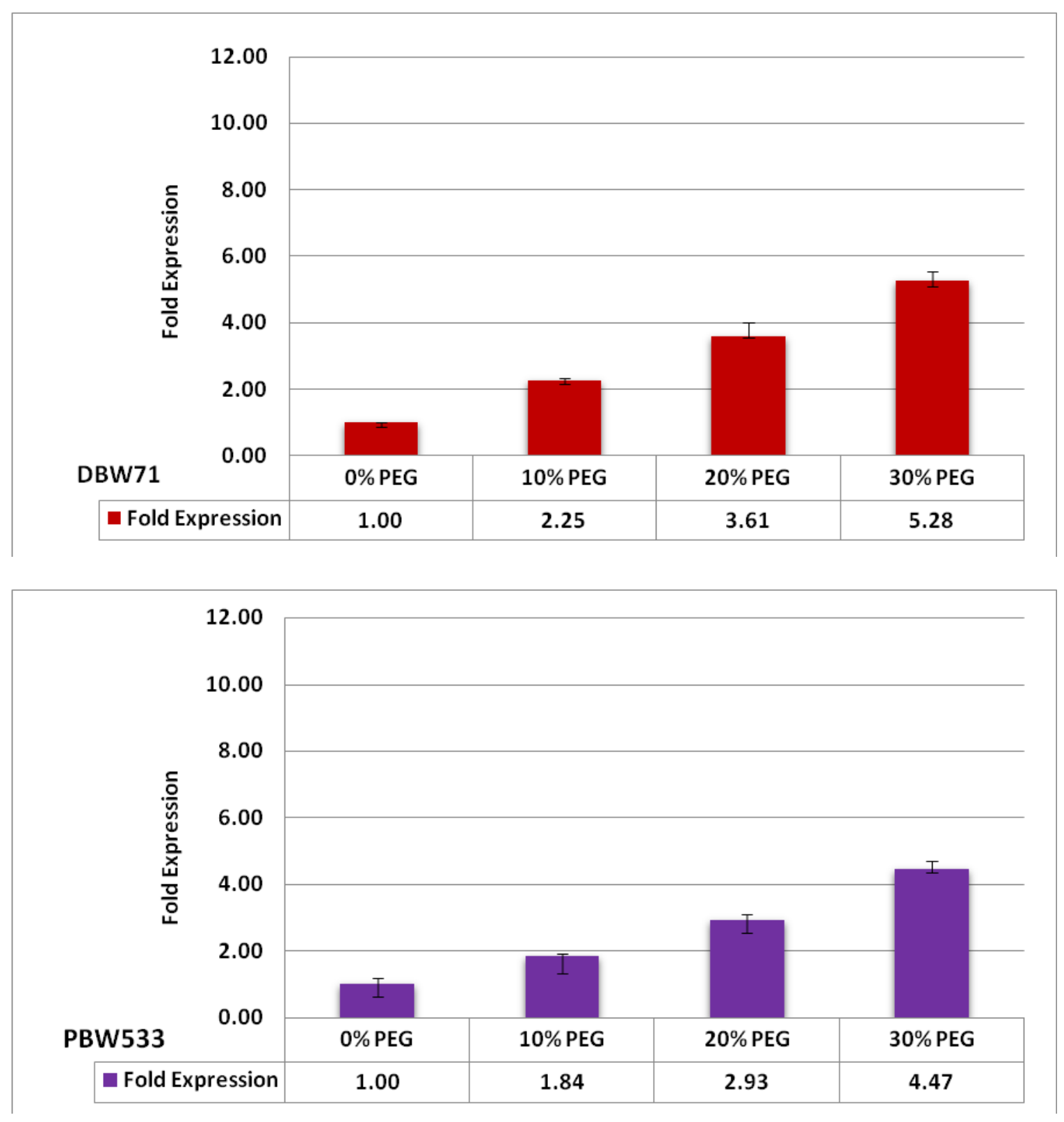

The gene specific primer has been proven to play essential roles in terms of expression level against the drought stress in wheat. The expression level was quantitatively analyzed using quantitative real time PCR with CHS gene specific primer. The expression level of CHS gene at different level of polyethylene glycol treatment for inducing drought stress is representing graphically by the difference in expression fold value in reference to control.

As the result indicated, the four wheat genotypes showed different expression pattern of CHS gene with primer qCHS. In genotype HD2733 the expression of CHS gene with primer qCHS is increased to 5.28, 
8.88 and 10.56 at $\mathrm{T} 1, \mathrm{~T} 2$ and $\mathrm{T} 3$ respectively in compression to fold value (1.0) of control sample. The same for genotype K9107 with same primer, the expression fold value of CHS gene is 2.97, 4.63 and 6.59 at T1, T2 and T3 respectively in compression to fold value (1.0) in control sample. Similarly in genotype DBW71, the expression of CHS gene with primer qCHS is increased to $2.25,3.61$ and 5.28 at $\mathrm{T} 1, \mathrm{~T} 2$ and $\mathrm{T} 3$ respectively in compression to fold value (1.0) control sample. The same for PBW533 with the same primer, the expression value of CHS gene is increased to $1.84,2.93$ and 4.47 at $\mathrm{T} 1, \mathrm{~T} 2$ and T3 respectively in compression to fold value (1.0) in control sample. The relative expression of TaCHS shows an increasing tendency with the increasing drought stress level from $\mathrm{T} 1$ to $\mathrm{T} 3$. However the result shows very high expression value for genotype HD2733 and K9107 as compared to genotype DBW71 and PBW533 at every level of polyethylene glycol concentration under imposed drought stress condition (Figure 1 and 2).

\section{References}

Brown D.E., Rashotte A.M., Murphy A.S., Tague B.W., Peer W.A., Taiz L. and Muday G.K. (2001). Flavonoids act as negative regulators of auxin transport in vivo in Arabidopsis thaliana. Plant Physiol., 126: 524-535.

Claudot A.C., Ernst D., Sandermann H. and Drouet A. (1999). Cloning and characterization of two members of the chalcone synthase gene family from walnut. Plan. Physiol. Biochem. 37(10): 721-730.

Dao T. T., Linthorst H. J. and Verpoorte R. (2011). Chalcone synthase and its functions in plant resistance. Phytochem. Rev.10. 397-412.

Dixon R.A., Harrison M.J. and Lamb-C. J. (1994). Early events in the activation of plant defense responses. Annu Rev Phytopath32:479-501.

Dooner H.K. (1983). Co-ordinate genetic regulation of flavonoid biosynthetic enzymes in maize. Genetics91:309-315.

Faulkner I.J. and Rubery P.H. (1992). Flavonoids and flavonoid sulphates as probes of auxin-transport regulation in Cucurbita pepo hypocotyl segments and vesicles. Planta186:618-625.

Ghaffari M., Toorchi M., Valizadeh M., Shakiba M.R. (2013). Morphophysiological screening of sunflower inbred lines under drought stress condition. Turk. J. Field Crops. 17. 185190.

Hahlbrock K. and Scheel D. (1989). Physiology and molecular biology of phenylpropanoid metabolism. Annu Rev Plant Physiol Plant Mol Biol., 40:347369.

Harrison M.J., Lawton M.A., Lamb C.J. and Dixon R.A. (1991). Characterization of a nuclear protein that binds to three elements within the silencer region of a bean chalcone synthase gene promoter. Proc Natl Acad Sci USA88:2515-2519.

Jacobs M. and Rubery P.H. (1988). Naturally occurring auxin transport regulators. Science 241:346-349.

Kreuzaler F., Ragg H., Fautz E., Kuhn D.N. and Hahlbrock K. (1983). UV-induction of chalcone synthase mRNA in cell suspension cultures of Petroselinum hortense. ProcNatlAcadSci USA. 80. 2591-2593.

Lunkenbein S., Coiner H., de Vos C.H.R., Schaart J.G., Boone M.J., Krens F.A., Schwab W., Salentijn E.M.J. (2006). Molecular characterization of a stable antisense chalcone synthase phenotype in strawberry (Fragaria $x$ ananassa). J. of Agri. and Food Chem. 54. 21452153.

Ma D., Sun D., Wang C., Li Y., and Guo T. (2014). Expression of flavonoid 
biosynthesis genes and accumulation of flavonoid in wheat leaves in response to drought stress. Plan. Physiol. and Biochem. 80. 60-66.

Marais J.P.J., Deavours B., Dixon R.A., Ferreira D. (2006). The Stereochemistry of Flavonoids. In The Science of Flavonoids, ed. E. Grotewold. Columbus, Ohio, USA: Springer.

Martin C.R. (1993). Structure, function and regulation of the chalcone synthase. Int Rev Cytol., 147:233-284.

Schroder J. and Schaafer E. (1980). Radio iodinated antibodies, a tool in studies on the presence and role of inactive enzyme forms: regulation of chalcone synthase in parsley cell suspension cultures. Arch Biochem Biophys. 203. 800-808.
Van der Meer I.M., Spelt C.E., Mol J.N.M. and Stuitje A.R. (1990).Promoter analysis of the chalcone synthase (chsA) gene of Petunia hybrida: a $67 \mathrm{bp}$ promoter region directs flower specific expression. Plant Mol Biol., 15: 95109.

Van der Meer I.M., Stuitje A.R., Mol J.N.M. (1993). Regulation of general phenylpropanoid and flavonoid gene expression. In: Verma DPS (ed) Control of plant gene expression. CRC Press, Boca Raton, 125-155.

Weisshaar B. and Jenkins G.I. (1998). Phenylpropanoid biosynthesis and its regulation. Current Opinion in Plant Biology. 1: 251-257.

\section{How to cite this article:}

Megha Singh, Vaishali and Lalit Kumar. 2020. Functional Analysis of Chalcone Synthase (Chs) Gene in Indian Wheat Cultivars in Response to Peg-Induced Drought Stress. Int.J.Curr.Microbiol.App.Sci. 9(10): 833-840. doi: https://doi.org/10.20546/ijcmas.2020.910.099 